Tropical Journal of Pharmaceutical Research August 2020; 19 (8): 1709-1714

ISSN: $1596-5996$ (print); 1596-9827 (electronic)

(C) Pharmacotherapy Group, Faculty of Pharmacy, University of Benin, Benin City, 300001 Nigeria.

\title{
Neuroprotective and anti-inflammatory effects of myricetin 3-glucoside in a rat model of cerebral ischemia
}

\author{
Shengshou $\mathrm{Ye}^{1 *}$, Jing $\mathrm{Ma}^{2}$, Chunhua $\mathrm{Ye}^{3}$, Xinlan Wang ${ }^{1}$ \\ ${ }^{1}$ Department of Neurology, ${ }^{2}$ Department of Emergency, Qinghai Province Cardiovascular and Cerebrovascular Disease \\ Specialist Hospital, ${ }^{3}$ Department of Nuclear Medicine, Qinghai Provincial People's Hospital, Xining, Qinghai 810000, China \\ *For correspondence: Email: yeshengshou@163.com; Tel: 0086-0971-6285704
}

Sent for review: 24 March 2020

Revised accepted: 18 July 2020

\begin{abstract}
Purpose: To investigate the effect of myricetin 3-glucoside (M3GLS) on middle cerebral artery occlusion (MCAO)-induced cerebral ischemia in a rat model, and the mechanism of action involved. Methods: A cerebral ischemia rat model was established using MCAO under $10 \%$ chloral hydrate anesthesia. Neurological severity score was determined by analyzing reflex, motor and sensory functions, as well as balancing potential. Infarction volume was determined using triphenyl tetrazolium chloride dye, while counting of Nissl bodies was done after toluidine blue staining. The protein expression levels of Bax and Bcl-2 were assayed using western blotting, while cytokine levels were determined by enzyme-linked immunosorbent assay (ELISA).

Results: Treatment of cerebral ischemia rats with M3GLS effectively reduced infarct volume, when compared to vehicle-treated group $(p<0.05)$. Moreover, M3GLS treatment significantly increased the population of Nissl bodies and effectively improved neurologic scores $(p<0.05)$. In M3GLS-pretreated rats, cerebral ischemia-induced elevation of protein expressions of TNF- $\alpha$, IL- 6 and IL-1 $\beta$ were significantly suppressed. M3GL treatment significantly reversed cerebral ischemia-mediated downregulation of Bcl-2 protein level, but markedly reduced cerebral ischemia-induced upregulation of Bax protein level $(p<0.05)$

Conclusion: M3GLS exerts protective effect against cerebral ischemia-induced brain injury in rats via downregulation of inflammatory cytokines. It reduces infarction volume in the brain of cerebral ischemia rats, and regulates Bcl-2/Bax protein ratio. Thus, M3GLS has a potential for use in the clinical management of cerebral ischemia.
\end{abstract}

Keywords: Myricetin, Neuroprotection, Anti-inflammation, Cerebral ischemia, Cytokines, Infarction

\begin{abstract}
This is an Open Access article that uses a fund-ing model which does not charge readers or their institutions for access and distributed under the terms of the Creative Commons Attribution License (http://creativecommons.org/licenses/by/4.0) and the Budapest Open Access Initiative (http://www.budapestopenaccessinitiative.org/read), which permit unrestricted use, distribution, and reproduction in any medium, provided the original work is properly credited.

Tropical Journal of Pharmaceutical Research is indexed by Science Citation Index (SciSearch), Scopus, International Pharmaceutical Abstract, Chemical Abstracts, Embase, Index Copernicus, EBSCO, African Index Medicus, JournalSeek, Journal Citation Reports/Science Edition, Directory of Open Access Journals (DOAJ), African Journal Online, Bioline International, Open-J-Gate and Pharmacy Abstracts
\end{abstract}

\section{INTRODUCTION}

Cerebral ischemia is one of the leading causes of long-term disabilities, and it is globally associated with high mortality. Reduced cerebral blood supply is considered a major cause of ischemic injury $[1,2]$. Decline in blood flow leads to depletion of oxygen supply, $\mathrm{Ca}^{2+}$ ion overload, free radical formation, and mitochondrial and DNA damage in neuronal cells [1,2]. These cellular events result in necrosis and apoptosis of brain cells. Studies have found that inflammatory processes, excitotoxicity and depolarizations due to infarcts and apoptosis are associated with 
cerebral ischemia [3,4]. Ischemia causes activation and accumulation of microglial cells and leukocytes in brain tissues, leading to inflammatory injury. Various molecular factors secreted during cerebral ischemia activate constituents of innate immunity and inflammatory pathways [5]. The cytokines usually linked to ischemia-mediated cell damage are tumor necrosis factor- $\alpha$ (TNF- $\alpha$ ), interleukin (IL)-1 $\beta$ and IL-6. These cytokines promote leukocyte accumulation, leading to elimination of nerve cells via apoptosis or necrosis, which results in cerebral infarction [6].

The B-cell lymphoma-2 (Bcl-2) protein family plays a prominent role in cerebral ischemia and brain cell damage. The regulation of apoptosis involves protein expressions of Bcl-2 and Bax: while $\mathrm{Bcl}-2$ is anti-apoptotic, Bax is pro-apoptotic [7]. Ischemia is followed by dephosphorylation of Bax, and its subsequent translocation from the cytosol to the mitochondria in the brain cells [8]. Oligomerization of Bax and its activation results in secretion of pro-apoptotic proteins from intermembrane mitochondrial space, leading to apoptosis [9].

Myricetin is a flavonoid with various pharmacological effects such as anti-inflammatory, radical-quenching and anti-apoptotic properties [10,11]. Studies have reported that myricetin exhibited protective effects against ischemia-mediated acute injury through diverse mechanisms [12]. The present study investigated the effect of myricetin 3glucoside (Figure 1) on MCAO-induced cerebral ischemia in rats.

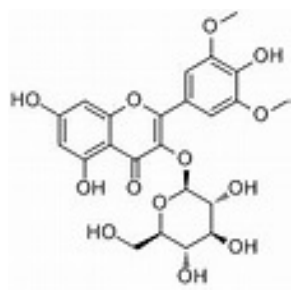

Figure 1: Structure of myricetin 3-glucoside

\section{EXPERIMENTAL}

\section{Animals}

Thirty-three 9-week old male Sprague-Dawley rats weighing 230-255 $\mathrm{g}$ were supplied by the Vital River Laboratories, Beijing (China). The rats were housed under standard laboratory conditions at temperature of $23-24{ }^{\circ} \mathrm{C}$ and humidity of $56-63 \%$ in an environment with 12-h light/12-h dark cycle. Access to feed and water was given ad libitum. The rats were assigned to three groups: sham-operated, vehicle-treated and M3GLS-treated groups. The animal experiments were carried out in line with the guidelines of the National Institute of Health, China [1]. The study was approved by the Ethics Committee for the Medical Ethics and Human Clinical Trials, Xijing Hospital, China (approval no. XHC/17/0076).

\section{Reagents}

Myricetin 3-glucoside (M3GLS, CAS number = 529-44-2) and dimethyl sulfoxide (DMSO) were purchased from Sigma-Aldrich, USA. A stock solution of M3GLS was prepared in normal saline and kept at $-40{ }^{\circ} \mathrm{C}$ before administration to the rats.

\section{Rat model of middle cerebral artery occlusion}

A rat model of MCAO was successfully established using previously reported methodology $[13,14]$. Under $10 \%$ chloral hydrate anesthesia, the rats were subjected to MCAO for $2 \mathrm{~h}$ prior to $24 \mathrm{~h}$ of reperfusion [15]. Rats in the treatment group were intragastrically administered M3GLS at a single dose of $5 \mathrm{mg} / \mathrm{kg}$ for $1 \mathrm{~h}$ before MCAO exposure. The sham and vehicle control rats were given equivalent volumes of normal saline in place of drug. After $24 \mathrm{~h}$, the rats were sacrificed via decapitation procedure under pentobarbital anesthesia (35 $\mathrm{mg} / \mathrm{kg}$ ).

\section{Neurological severity score}

The neurological severity score of rats was independently determined by 3 observers after $24 \mathrm{~h}$ of MCAO treatment. Each of the observers carried out 3 assessments prior to assigning the neurological severity score. Other parameters determined during scoring were reflex, motor and sensory functions, as well as balancing potential. The grading scale used consisted of scores from $0-18$, with higher values indicating more severe injury [16].

\section{Measurement of infarct volume}

After $24 \mathrm{~h}$ of MCAO exposure, the rats were sacrificed via decapitation under pentobarbital anesthesia (35 mg/kg), and their brains were excised immediately and cut into 2-mm sections. The sections were stained with $1 \%$ triphenyl tetrazolium chloride (TTC; Amresco, LLC, USA) in the dark for $20 \mathrm{~min}$ at $37^{\circ} \mathrm{C}$, followed by fixing in formaldehyde (4\%). The presence of waxy areas without staining in brain samples indicated infarction; the volume of infarction relative to total sample area was determined [17].

Trop J Pharm Res, August 2020; 19(8): 1710 


\section{Nissl staining test}

The rat brain samples were excised and immersed for $30 \mathrm{~h}$ in $10 \%$ neutral-buffered formalin, after which they were embedded in paraffin. The samples were sliced into 2-mm sections, dewaxed and then rehydrated in ethyl alcohol. Thereafter, the sections were stained with $0.5 \%$ Toluidine Blue (Sigma-Aldrich, St. Louis, MO, USA), and visualized under Eclipse Ti-U Inverted Microscope (Nikon Corporation, Tokyo, Japan). Nissl bodies in the brain samples were counted using Image-Pro Plus version 6.0 (Media Cybernetics, Inc, Rockville, MD, USA).

\section{Determination of expression levels of inflammatory cytokines}

Rat brain homogenates were prepared at $4{ }^{\circ} \mathrm{C}$ and the homogenates were centrifuged at the same temperature for $20 \mathrm{~min}$ at $5,000 \mathrm{x} \mathrm{g}$. The supernatants obtained were subjected to measurement of inflammatory cytokines using ELISA kits (Cusabio Biotech Co. Ltd) as per the manufacturer's protocol. The ELISA kits used were for TNF- $\alpha$ (CAS number CSB-E11987r), IL6 (CAS number CSB-E04640r) and IL-1 1 (CAS numberCSB-E08055r).

\section{Western blotting assay}

Rat brain tissues were excised and subsequently homogenized in RIPA-lysis buffer (Beyotime Institute of Biotechnology, Haimen China). The homogenates were centrifuged at $4{ }^{\circ} \mathrm{C}$ for $25 \mathrm{~min}$ at $12,000 \times \mathrm{g}$, and their protein contents were assayed using bicinchoninic acid assay kit. Then, protein samples (50 $\mathrm{ug}$ per lane) were resolved on $10 \%$ SDS-PAGE and subsequently transferred to PVDF membranes. The membranes were incubated for $1 \mathrm{~h}$ with $5 \%$ skim milk powder solution containing TBST at $37{ }^{\circ} \mathrm{C}$. Thereafter, the membranes were incubated at 4 ${ }^{\circ} \mathrm{C}$ overnight with primary antibodies for Bax (1:1000 dilution; cat no. 50599-2-lg); Bcl-2 (1:1000 dilution; cat no. 12789-1-AP), and GAPDH (1:1,000 dilution; cat no. 60004-1-lg). Following washing with PBS, the membranes were incubated for $1 \mathrm{~h}$ at room temperature with horseradish peroxidase-conjugated goat antimouse IgG secondary antibody. Visualization of the immuno-positive bands was performed using BeyoECL Star (Beyotime Institute of Biotechnology).

\section{Statistical analysis}

Data are presented as mean \pm standard deviation (SD) of triplicate measurements. The data were analyzed using SPSS, version 17.0
(SPSS, Inc., Chicago, IL, UA). Statistical analysis was carried out with one-way analysis of variance (ANOVA), followed by Dunnett's test. Differences were assumed statistically significant at $p<0.05$.

\section{RESULTS}

\section{M3GLS mitigated cerebral ischemia-induced brain injury in rats}

Infarct volumes were significantly higher in vehicle-treated rats after $24 \mathrm{~h}$ of cerebral ischemia than in M3GLS-treated rats (Figure 2). Treatment of cerebral ischemia rats with M3GLS effectively reduced volume of infarcts, when compared to vehicle-treated group.

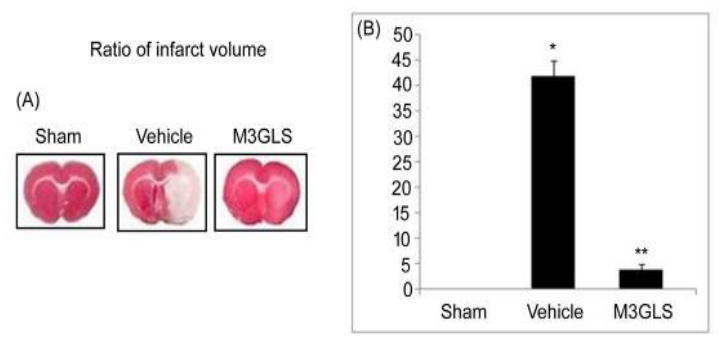

Figure 2: Effect of M3GLS on brain injury. (A) M3GLS pre-treated rats were subjected to MCAO, and volumes of infarcts were measured at $24 \mathrm{~h}$ using TTC stain. (B) Degree of TTC staining in brain tissues; * $p<$ $0.049 ;{ }^{* *} p<0.009$ vs. untreated group

\section{M3GLS increased population of Nissl bodies in rats with cerebral ischemia}

Cerebral ischemia caused significant reduction in the count of Nissl bodies in rat brain tissues at 24 h (Figure 3). The count of Nissl bodies decreased to $178.19 \pm 17.23$ in vehicle-treated group, when compared to $498.65 \pm 23.72$ in sham-operated rats. However, treatment of the cerebral ischemia rats with M3GLS significantly enhanced the count of Nissl bodies, when compared to vehicle group $(p<0.05)$.

\section{M3GLS suppressed cerebral ischemia-} induced increase in neurological scores

Neurological scores of rats were determined by measuring behavioral deficits during $120 \mathrm{~min}$ of cerebral ischemia (Figure 4). The vehicle-treated cerebral ischemia rats showed high neurological scores which were evident in their inability to walk successfully, failure to balance on beams, and occasional circling towards the right. However, M3GLS pre-treatment of cerebral ischemia rats effectively reduced the increases in neurological scores. 


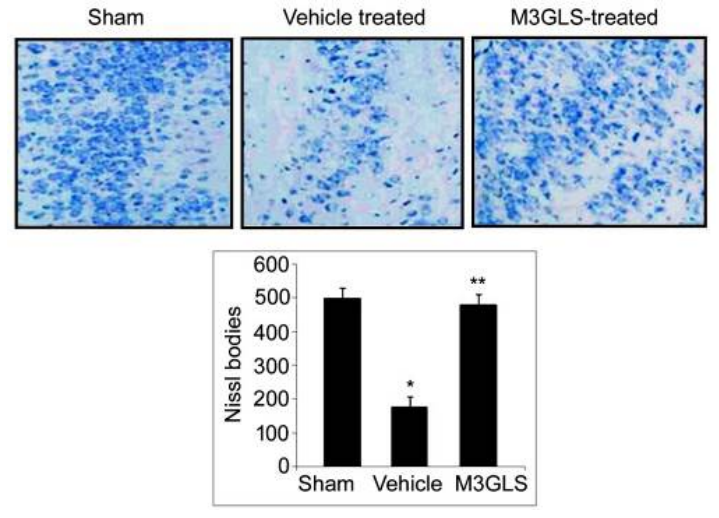

Figure 3: Effect of M3GLS on Nissl staining in brain tissues of cerebral ischemic rats $(A)$. Rats pretreated with M3GLS were subjected to MCAO and then analyzed for Nissl-positive cells. (B) Nissl-positive cells in the brain tissues. ${ }^{*} P<0.049 ;{ }^{* *} p<0.009$ vs. untreated group

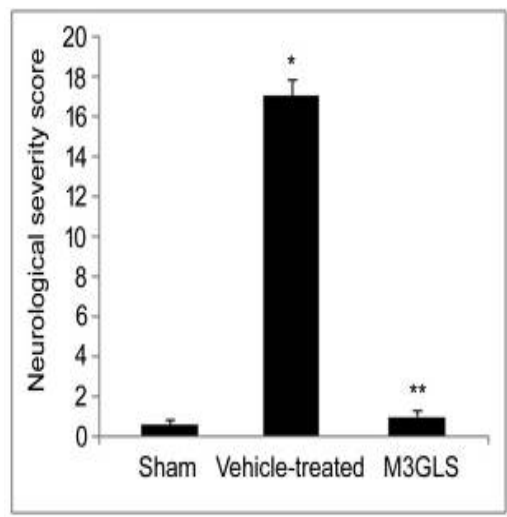

Figure 4: Effect of M3GLS on neurological scores in cerebral ischemia rats. Rats pretreated with M3GLS were subjected to MCAO, and neurological scores were determined during 120 min of cerebral ischemia. ${ }^{*} P<0.049 ;{ }^{* *} p<0.009$ vs. untreated group

\section{M3GLS suppressed cerebral ischemia- induced inflammation}

Cerebral ischemia significantly upregulated the expressions of TNF- $\alpha$, IL- 6 and IL- $1 \beta$ in the brain tissue, when compared to sham-operated group (Figure 5). However, the cerebral ischemiainduced increases in expressions of TNF- $\alpha$, IL-6 and IL-1 $\beta$ proteins were significantly suppressed in M3GLS-pretreated rats.

\section{M3GLS suppressed cerebral ischemia- induced activation of apoptotic signaling}

Cerebral ischemia significantly decreased the protein expression level of Bcl-2, when compared to the sham-operated rats (Figure 6). However, M3GLS treatment markedly alleviated the cerebral ischemia-mediated suppression of Bcl-2 protein level, when compared to the untreated group. Moreover, cerebral ischemia significantly increased Bax protein level in rats, when compared to the sham-operated group. However, the cerebral ischemia-induced upregulation of Bax protein expression was significantly suppressed in rats on treatment with M3GLS. Thus, M3GLS treatment regulated the protein ratio of $\mathrm{Bcl}-2 / \mathrm{Bax}$ in cerebral ischemia rats.

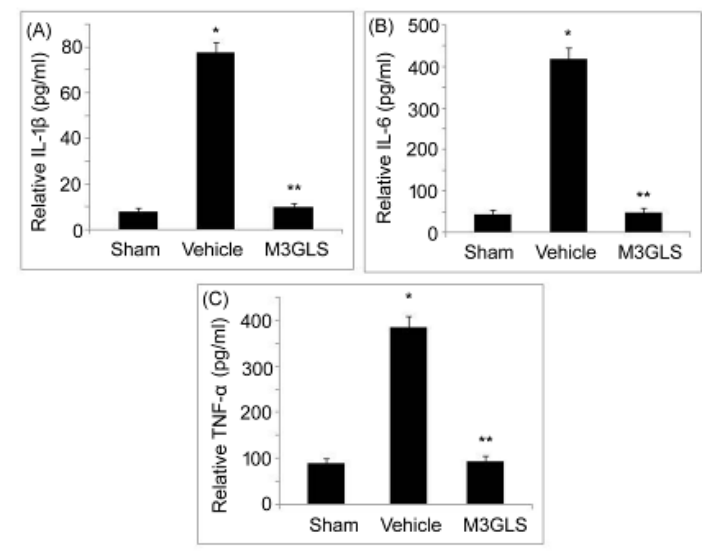

Figure 5: Effect of M3GLS on brain inflammation in cerebral ischemia rats. Levels of (A) TNF- $\alpha$, (B) IL-6 and $(C) I L-1 \beta$ in rats pretreated with M3GLS and subjected to MCAO exposure, as measured using ELISA assay; ${ }^{*} p<0.049 ;{ }^{* *} p<0.009$ vs. untreated group

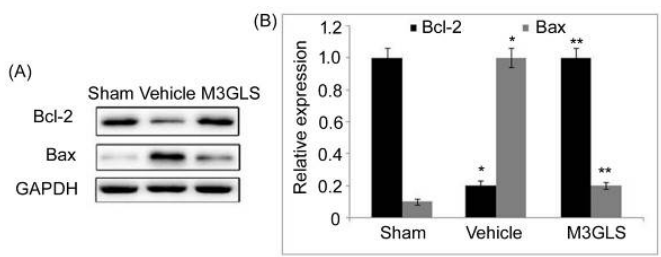

Figure 6: Effect of M3GLS on levels of $\mathrm{Bcl}-2$ and $\mathrm{Bax}$ in cerebral ischemia rats. (A) The M3GLS pre-treated rats were subjected to MCAO and protein expressions in brain tissues were measured using western blotting. (B) Protein expression levels, with GAPDH as control. (C) $\mathrm{Bcl}-2 / \mathrm{Bax}$ ratios. ${ }^{*} P<0.049$; ${ }^{* *} p<0.009$ vs. untreated group

\section{DISCUSSION}

Ischemic stroke leads to inflammation which is associated with development of lesions through poorly understood mechanisms [18]. Cerebral ischemia-mediated neuronal degeneration initiates immune response aimed at elimination of cell debris and regeneration. Inflammatory response generally leads to cerebral damage which results in secondary injuries [19, 20]. The present study investigated the protective potential of M3GLS against cerebral ischemiainduced brain injury. Results from TTC-staining 
showed larger volumes of infarcts in vehicletreated cerebral ischemia rats than in rats in sham group. The volume of infarcts was markedly lower in M3GLS-treated cerebral ischemia rats than in vehicle-treated group.

The count of Nissl bodies in brain tissues of rats was reduced significantly by cerebral ischemia, relative to sham group. However, the cerebral ischemia-mediated decrease in count of Nissl bodies was significantly reversed in rat brain tissues by M3GLS treatment. Moreover, cerebral ischemia significantly increased neurological scores in vehicle-treated rats. However, M3GLS pre-treatment of cerebral ischemia rats effectively suppressed the increase in neurologic scores. These findings indicate that M3GLS exerts neuro-protective potential against cerebral ischemia-induced brain injury in rats.

Activation of glial cells and cerebrovascular endothelial cells by various inflammatory mediators leads to ischemic injury [21]. Cytokines are the main inflammatory mediators with well-established roles in ischemic injury $[22,23]$. Cytokine expressions are enhanced by ischemic injury which subsequently leads to neuronal cell necrosis $[22,23]$. Stroke-induced tissue injury is modulated by various cytokines such as TNF- $\alpha$, IL-1 $\beta$ and IL- 6 which are considered important targets in development of treatments for stroke [24]. Infarction volume in brain samples is associated with the viability of cytokines in ischemic penumbra at early stage of stoke [23]. The neuroprotective properties of various bioactive compounds are significant in animal models of stroke [22].

In the present study, cerebral ischemia significantly increased levels of TNF- $\alpha$, IL- 6 and $\mathrm{IL}-1 \beta$ in the brain tissues, when compared to the sham-operated group. Pre-treatment with M3GLS significantly suppressed the cerebral ischemia-induced elevations in protein expression levels of TNF- $\alpha, \mathrm{IL}-6$ and IL- $1 \beta$. The $\mathrm{Bcl}-2$ protein level in cerebral ischemia rat brain tissues was lowered significantly, while Bax protein was elevated. However, pre-treatment with M3GLS reversed cerebral ischemia-induced lowering of $\mathrm{Bcl}-2$ protein and elevation of $\mathrm{Bax}$ protein level in rat brain samples. Myricetin 3glucoside treatment maintained $\mathrm{Bcl}-2 / \mathrm{Bax}$ protein ratio in rats with cerebral ischemia.

\section{CONCLUSION}

The results obtained in this study indicate that M3GLS exerts protective effect against cerebral ischemia-induced brain injury in rats by inhibiting inflammatory cytokines. Moreover, M3GLS lowers infarction volume in the brain of cerebral ischemia rats, and regulates $\mathrm{Bcl}-2 / \mathrm{Bax}$ protein ratio. Thus, M3GLS is a potential drug candidate for the management of cerebral ischemia.

\section{DECLARATIONS}

\section{Conflict of interest}

No conflict of interest is associated with this work.

\section{Contribution of authors}

We declare that this work was done by the author(s) named in this article and all liabilities pertaining to claims relating to the content of this article will be borne by the authors. Shengshou $\mathrm{Ye}$ - conceived and designed the study; Jing Ma, Chunhua Ye, Xinlan Wang collected and analyzed the data, while Jing Ma, Chunhua Ye wrote the manuscript. All authors read and approved the manuscript for publication.

\section{Open Access}

This is an Open Access article that uses a funding model which does not charge readers or their institutions for access and distributed under the terms of the Creative Commons Attribution License (http://creativecommons.org/licenses/by/ 4.0) and the Budapest Open Access Initiative (http://www.budapestopenaccessinitiative.org/rea d), which permit unrestricted use, distribution, and reproduction in any medium, provided the original work is properly credited.

\section{REFERENCES}

1. Chen Y, Zhang L, Ni J, Wang X, Cheng J, Li Y, Zhen X, Cao T, Jia J. LLDT-8 protects against cerebral ischemia/reperfusion injury by suppressing post-stroke inflammation. J Pharmacol Sci 2016; 131: 131-137.

2. Shim R, Wong CHY. Ischemia, Immunosuppression and Infection--Tackling the Predicaments of Post-Stroke Complications. Int J Mol Sci 2016; 17: 64.

3. Broughton BR, Reutens DC, Sobey CG. Apoptotic mechanisms after cerebral ischemia. Stroke 2009; 40: e331-e339.

4. Dirnagl U, ladecola C, Moskowitz MA. Pathobiology of ischaemic stroke: An integrated view. Trends Neurosci 1999; 22: 391-397.

5. Murakami A, Nakamura $Y$, Tanaka $T$, Kawabata K, Takahashi D, Koshimizu K, Ohigashi H. Suppression by citrus auraptene of phorbol ester-and endotoxin-induced inflammatory responses: Role of attenuation of leukocyte activation. Carcinogenesis 2000; 21: 18431850.

Trop J Pharm Res, August 2020; 19(8): 1713 
6. Farhoudi $M$, Najafi-Nesheli $M$, Hashemilar $M$, Mahmoodpoor A, Sharifipour E, Baradaran B, Taheraghdam A, Savadi-Oskouei D, Sadeghi-Bazargani $H$, Sadeghi-Hokmabadi E, et al. Effect of $I M O D^{\mathrm{TM}}$ on the inflammatory process after acute ischemic stroke: $A$ randomized clinical trial. Daru 2013; 21: 26.

7. Niizuma K, Yoshioka H, Chen H, Kim GS, Jung JE, Katsu M, Okami N, Chan PH. Mitochondrial and apoptotic neuronal death signaling pathways in cerebral ischemia. Biochim Biophys Acta 2010; 1802: 92-99.

8. Saito A, Hayashi T, Okuno S, Ferrand-Drake M, Chan $\mathrm{PH}$. Overexpression of copper/zinc superoxide dismutase in transgenic mice protects against neuronal cell death after transient focal ischemia by blocking activation of the bad cell death signaling pathway. J Neurosci 2003; 23: 1710-1718.

9. Fiskum G, Murphy AN, Beal MF. Mitochondria in neurodegeneration: Acute ischemia and chronic neurodegenerative diseases. J Cereb Blood Flow Metab 1999; 19: 351-369.

10. Majid M, Khan MR, Shah NA, UI Haq I, Farooq MA, Ullah S, Sharif A, Zahra Z, Younis T, Sajid M. Studies on phyto-chemical, antioxidant, anti-inflammatory and analgesic activities of Euphorbia dracunculoides. BMC Complement Altern Med 2015; 15: 349.

11. Mendes V, Vilaça R, de Freitas V, Ferreira PM, Mateus $N$, Costa V. Effect of myricetin, pyrogallol, and phloroglucinol on yeast resistance to oxidative stress. Oxid Med Cell Longev 2015; 2015: 782504.

12. Qiu Y, Cong N, Liang M, Wang Y, Wang J. Systems pharmacology dissection of the protective effect of M3GLSagainst acute ischemia/reperfusion-induced myocardial injury in isolated rat heart. Cardiovasc Toxicol 2017; 17: 277-286.

13. Satoh $T$, Kosaka K, Itoh $K$, Kobayashi A, Yamamoto $M$, Shimojo Y, Kitajima C, Cui J, Kamins J, Okamoto S, et al. Carnosic acid, a catechol-type electrophilic compound, protects neurons both in vitro and in vivo through activation of the Keap1/Nrf2 pathway via Salkylation of targeted cysteines on Keap1. J Neurochem 2008; 104: 1116-1131.

14. Wang N, Wu L, Cao Y, Wang Y, Zhang Y. The protective activity of imperatorin in cultured neural cells exposed to hypoxia re-oxygenation injury via anti-apoptosis. Fitoterapia 2013; 90: 38-43.
15. Hwang SY, Shin JH, Hwang JS, Kim SY, Shin JA, Oh ES, Oh S, Kim JB, Lee JK, Han IO. Glucosamine exerts a neuroprotective effect via suppression of inflammation in rat brain ischemia/reperfusion injury. Glia 2010; 58: 1881-1892.

16. Wang C, Pei A, Chen J, Yu H, Sun ML, Liu CF, Xu X. A natural coumarin derivative esculetin offers neuroprotection on cerebral ischemia/reperfusion injury in mice. J Neurochem 2012; 121: 1007-1013.

17. Denes A, Ferenczi S, Kovács KJ. Systemic inflammatory challenges compromise survival after experimental stroke via augmenting brain inflammation, blood- brain barrier damage and brain oedema independently of infarct size. J Neuroinflammation 2011; 8: 164.

18. Kamel H, ladecola C. Brain-immune interactions and ischemic stroke: Clinical implications. Arch Neurol 2012; 69: 576-581.

19. Brea $D$, Sobrino $T$, Ramos-Cabrer P, Castillo J. Inflammatory and neuroimmunomodulatory changes in acute cerebral ischemia. Cerebrovasc Dis 2009; 27 (Suppl 1): S48-S64.

20. Benakis C, Vaslin A, Pasquali C, Hirt L. Neuroprotection by inhibiting the c-Jun N-terminal kinase pathway after cerebral ischemia occurs independently of interleukin- 6 and keratinocyte-derived chemokine (KC/CXCL1) secretion. J Neuroinflammation 2012; 9: 76.

21. Hamishehkar $H$, Beigmohammadi MT, Abdollahi $M$, Ahmadi A, Mahmoodpour A, Mirjalili MR, Abrishami R, Khoshayand MR, Eslami $K$, Kanani $M$, et al. Identification of enhanced cytokine generation following sepsis. Dream of magic bullet for mortality prediction and therapeutic evaluation. Daru 2010; 18: 155-162.

22. Lambertsen $K L$, Biber $K$, Finsen $B$. Inflammatory cytokines in experimental and human stroke. J Cereb Blood Flow Metab 2012; 32: 1677-1698.

23. Pradillo JM, Denes A, Greenhalgh AD, Boutin H, Drake C, McColl BW, Barton E, Proctor SD, Russell JC, Rothwell NJ, Allan SM. Delayed administration of interleukin-1 receptor antagonist reduces ischemic brain damage and inflammation in comorbid rats. J Cereb Blood Flow Metab 2012; 32: 1810-1819.

24. Xu Y, Wang JY, Song XH, Qu LD, Wei RL, He FP, Wang $K$, Luo BY. RIP3 induces ischemic neuronal DNA degradation and programmed necrosis in rat via AIF. Scientific Reports 2016; 6: 29362. 